\title{
Simplified Calculation and Computer Comparison of Wall Beam
}

\author{
Lei Zhang $^{1}$ \\ ${ }^{1}$ Department of Civil Engineering, Central South University, Changsha, Hunan 410075, China
}

\begin{abstract}
Given the problems existing in the design method of wall beam in criterion GBJ3-88, the distribution of stress and internal force is investigated by the finite element analysis of simply supported wall beams, and the approximate calculation formula of internal force of the supporting beam and the simplified calculation formula for bearing capacity is proposed.
\end{abstract}

\section{Introduction}

The criterion for the Design of Masonry Structures "(GBJ3-88) is first included in the design of wall beams according to the domestic test study of simply supported wall beams and finite element analysis. The limit state design method considering the combination of wall and beam is adopted. The test of domestic 258 simply supported wall beams shows the bending failure of the composite beam and the shear failure of the wall. The supporting beam and the local compression failure of the upper masonry of the supporting beam will occur under the action of the top surface load [1-3]. The criterion states that the load on the top surface of the wall beam Q2, which considers the reduction coefficient of the floor load. The bearing capacity of the cross-section and the section of the hole edge of the bracket is calculated by eccentric tension. The shear bearing capacity of the inclined section of the bracket is calculated according to the bending member (support section) and the deflection member (hole side section) respectively. The $\xi 2$ and $\xi 3$ of the influence coefficient of the hole and the concentrated load consider the shear capacity of the wall based on the experimental design formula, but the calculation is actually more complicated. Specification for simply supported wall beams, a simple rule is made for the single-span frame supporting wall beam. Simply supported wall beams are seldom used in engineering. However, this is the basic component of the GBJ3-88 that is involved in the design of the wall beam. Based on experimental research and finite element analysis, this paper proposes a simplified calculation method of bearing capacity of the bracket and provides some suggestions for the improvement of checking calculation of the wall bearing capacity[4-7].

Engineering background: Hunan Economic Development Zone. The building height is $38.05 \mathrm{~m}$. The construction area is $9212.1 \mathrm{~m}^{2}$, the first floor is $4.2 \mathrm{~m}$, and the others are $3.3 \mathrm{~m}$, per layer $2.8 \mathrm{~m}$. for ten layers, the first-floor area is $1105.2 \mathrm{~m}^{2}$, the second-floor area of $984.58 \mathrm{~m}^{2}$, the whole building area is $820.1 \mathrm{~m}^{2}$; The total roof room/staircase/water tank building area of the * Corresponding author: Leizhang12345@outlook.com building is $561.6 \mathrm{~m}^{2}$. The specific situation is shown in the structural plane layout and profile. The seismic fortification intensity is 7 degrees, the design basic seismic acceleration is $g$, the roof waterproofing class is II, the building fire resistance grade is two[8-9].

\section{Methodology}

After obtaining the results of internal force analysis under various loads, all the components of the structure are combined with internal forces. The specific combination method is shown in the internal force combination table. The left and right beam ends and the middle section of the span are the most unfavourable sections, and for columns, the top and bottom of the columns are the most unfavourable sections. The bottom layer, top layer AB, $\mathrm{BC}$ span beam are taken here, as well as the bottom layer, five layers and column A, column B for internal force combination. Because of the need to consider seismic fortification, the internal force basis of section design is determined after considering the combination of nonseismic internal force. The combination of seismic effect and other load effects in the frame beam used for bearing capacity calculation is shown in the table. Because the seismic requirements should consider strong shear and weak bending, the shear force of the beam can be adjusted according to the seismic grade of the frame. $6.1 \mathrm{~m}$ is the net span of the beam, while 0.75 is the bearing capacity adjustment coefficient of the beam end bending moment in the composite table. When calculating the shear force, it should be divided, and the internal force should be reduced. The basic combination of seismic effect and other load effects are shown in the table. Due to the requirements of seismic design, the bending moment at the end of the column should not only consider the general combination but also consider the action of the strong column and the weak beam. The combined value of column bending moment is obtained according to the stiffness ratio of the column end line.

Finally, the combination of the internal force standard value and the design value is adopted for the foundation 
design, because the standard value is used in the calculation of the base area, and the design value is used in checking the calculation of the foundation height and the calculation of the base reinforcement. The bending moment diagram at constant load is shown in Fig.1, and the calculation of the bending moment diagram is shown in Fig.2.

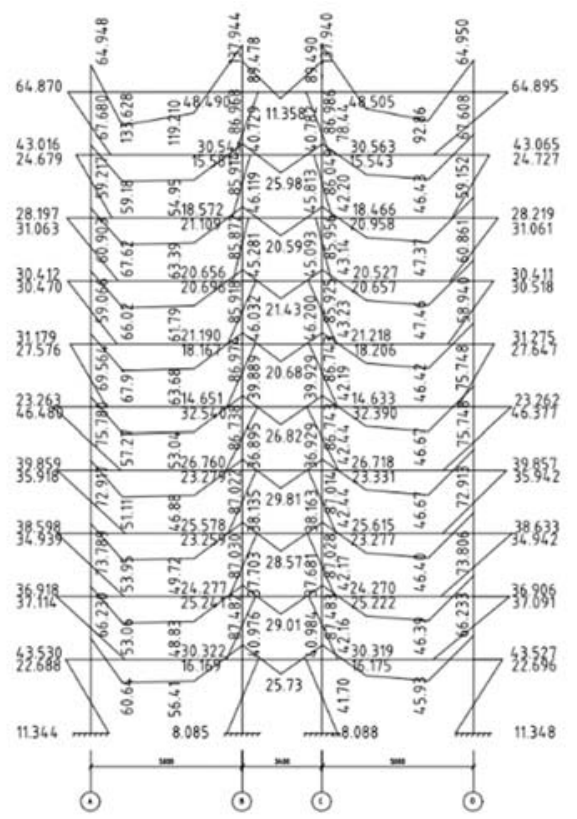

Fig. 1. Bending moment diagram at constant load

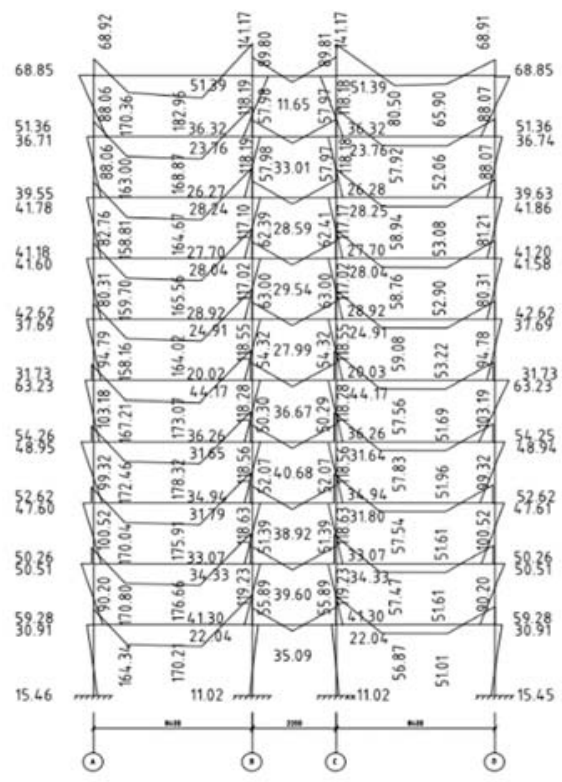

Fig. 2. Calculation of the bending moment diagram

\subsection{Verification and calculation of internal forces}

In order to select the most unfavorable internal force combination in the actual calculation of the internal force, it is worth comparing the combination of seismic and nonseismic internal forces:

Left: $\mathrm{M}=-309.10 \mathrm{kN} \cdot \mathrm{m} ; \mathrm{VM}=206.24 \mathrm{kN}$

Median: $\mathrm{M}=42.108 \mathrm{kN} \cdot \mathrm{m}$;

Right: $\mathrm{M}=-309.10 \mathrm{kN} \cdot \mathrm{m} ; \mathrm{VM}=-206.24 \mathrm{kN}$.

\subsection{Calculation of flexural capacity of the normal section}

Place the figure as close as possible after the point where it is first referenced in the text. If there is a large number of figures and tables it might be necessary to place some before their text citation. If a figure or table is too large to fit into one column, it can be centred across both columns at the top or the bottom of the page.

Concrete strength:

$\mathrm{C} 30, f_{c}=14.3 \mathrm{~N} / \mathrm{mm}^{2}, f_{t}=1.43 \mathrm{~N} / \mathrm{mm}^{2}, f_{t} k=$ $2.01 \mathrm{~N} / \mathrm{mm}^{2}$.

Reinforcement strength:

HPB300, $f_{y}=270 \mathrm{~N} / \mathrm{mm}^{2}, f_{y k}=300 \mathrm{~N} / \mathrm{mm}^{2}$.

$\mathrm{HRB} 400, f_{y}=360 \mathrm{~N} / \mathrm{mm}^{2}, f_{y k}=400 \mathrm{~N} / \mathrm{mm}^{2}$.

Relative boundary pressure zone height:

$\xi_{b}=0.518$

\subsubsection{The left bearing of 1-story BC beam}

Beam section size $300 \mathrm{~mm} \times 650 \mathrm{~mm}$; according to rectangular section calculation.

$h_{0}=h-a_{s}=650-35=615 \mathrm{~mm}$

$\alpha_{s}=\frac{M}{\alpha_{1} f_{c} b h_{0}^{2}}$

$=\frac{309.10 \times 10^{6} \mathrm{~N} \cdot \mathrm{mm}}{1.0 \times 14.3 \mathrm{~N} / \mathrm{mm}^{2} \times 300 \mathrm{~mm} \times(615 \mathrm{~mm})^{2}}$

$=0.1905$

$\xi=1-\sqrt{\left(1-2 \alpha_{s}\right)}=1-\sqrt{(1-2 \times 0.1905)}$

$=0.2132 \leq \xi_{b}=\min \{0.518,0.35\}$

$A_{s}=\frac{\alpha_{1} f_{c} b h_{0} \xi}{f_{y}}$

$=\frac{1.0 \times 14.3 \mathrm{~N} / \mathrm{mm}^{2} \times 300 \mathrm{~mm} \times 615 \mathrm{~mm} \times 0.2132}{360 \mathrm{~N} / \mathrm{mm}^{2}}$

$=1562.49 \mathrm{~mm}^{2}$

When not seismic,

$\rho_{\text {min }}=\max \left\{0.2 \%, \frac{45 f_{t}}{f_{y}} \%\right\}=0.2 \%$

In secondary seismic,

$\rho_{\text {min }}=\max \left\{0.3 \%, \frac{65 f_{t}}{f_{y}} \%\right\}=0.3 \%$

$A_{\text {Smin }}=\rho_{\text {min }} b h=0.003 \times 300 \mathrm{~mm} \times 650 \mathrm{~mm}$

$=585 \mathrm{~mm}^{2}$

Actual $A_{s}=1702 m m\left(\Psi_{320} \Psi_{222}\right)$

\subsubsection{Medium-span section (designed as $T$ beam)}

Determination of 1) flange width

Comparison

$b_{f}^{\prime}=\frac{3400}{3}=1133.33 \mathrm{~mm} \approx 1150 \mathrm{~mm}$

T section type judgment

$\alpha_{1} f_{c} b_{f}^{\prime} h_{f}^{\prime}\left(h_{0}-\frac{h_{f}^{\prime}}{2}\right)$

$=1.0 \times 14.3 \mathrm{~N} / \mathrm{mm}^{2} \times 1150 \mathrm{~mm}$

$=929.143 \mathrm{kN} \cdot \mathrm{m}>42.108 \mathrm{kN} \cdot \mathrm{m}$

Therefore, it belongs to the first kind of T section.

Calculation of steel bar area 


$$
\begin{aligned}
& \alpha_{s}=\frac{M}{\alpha_{1} f_{c} b_{f}^{\prime} h_{0}^{2}} \\
& =\frac{42.108 \times 10^{6} \mathrm{~N} \cdot \mathrm{mm}}{1.0 \times 14.3 \mathrm{~N} / \mathrm{mm}^{2} \times 1150 \mathrm{~mm} \times(615 \mathrm{~mm})^{2}} \\
& =0.0068 \\
& \xi=1-\sqrt{\left(1-2 \alpha_{s}\right)}=1-\sqrt{(1-2 \times 0.0068)} \\
& =0.0068 \leq \xi \_b=\min \{0.518,0.35\} \\
& A_{s}=\frac{\alpha_{1} f_{c} b_{f}^{\prime} h_{0} \xi}{f_{y}} \\
& =\frac{1.0 \times 14.3 \mathrm{~N} / \mathrm{mm}^{2} \times 1150 \mathrm{~mm} \times 615 \mathrm{~mm} \times 0.0068}{360 \mathrm{~N} / \mathrm{mm}^{2}} \\
& =191.04 \mathrm{~mm}^{2} \\
& A_{\text {Smin }}=\rho_{\text {min }} b h=0.003 \times 300 \mathrm{~mm}^{2} \times 650 \mathrm{~mm} \\
& =585 \mathrm{~m}
\end{aligned}
$$$$
\text { Actual } A_{s}=1018 \mathrm{~mm}^{2}\left(\Psi_{418}\right)
$$

\section{Conclusion}

The method employed in this paper does not consider the reduction of floor load by the wing wall. It is no longer required to check and calculate the mid-span section and the hole side section of the wall beam at the same time but the bending moment and axial tension formulas of the joists are directly provided to calculate the bearing capacity of the normal section, and the shear force is greatly increased to calculate the shear capacity of the oblique section of the joists. Considering the action of the top beam, the shear bearing capacity of the wall is improved.

\section{References}

1. Criterion for Design of Masonry Structures (GBJ 388). (1988). Beijing: China Construction Industry Press.

2. Tang, D. X. et al. (1992). Comment on the Application of New Criterion for masonry structure. Beijing: China Construction Industry Press.

3. Thematic Cluster of Wall Beams. Thematic Synthesis Report on Wall Beam Research. (1984). Guangzhou: South China Institute of Technology.

4. Feng M. S., Wang Q. L., et al. (1989). Experimental Study of Wall Beam And Design of Wall Beam Considering Combined Action. See: Masonry Structure Research Papers, Changsha: Hunan University Press.

5. Gong S. X., Tang K. Q. (1988). Experimental study and finite element analysis of working characteristics and calculation methods of simply supported wall beams. Journal of Zhengzhou Institute of Technology, 9(3).

6. Probability Statistics Group, Department of Mathematics and Mechanics, Peking University. Orthogonal Design Method. (1979). Beijing: Chemical Industry Press.

7. Zhou Y., Chen L. F., Li X., et al. (1999). Finite element analysis and simplified calculation of simply supported wall beams without openings. Engineering Mechanics Supplement.

8. Gong S. X., Guo L. G. (1999). Vertical load test of continuous wall beam and calculation of shear bearing capacity. See: development of masonry structure at the turn of the century. National Technical Committee of masonry structure Standards, Hangzhou. 